\title{
Power System Security by FACTS Devices using GA
}

\author{
Chandrashekhar S. Hiwarkar, Prakash G. Burade
}

\begin{abstract}
Now daily's electrical power necessity has expanded exponentially while the development and rebuilding of the electrical power framework for age and transmission in the power segment has been basically restricted because of present assets and natural conditions.

Accordingly, roughly of the halls of power transmission overhead lines are intensely stacked and clogged. Additionally the serious issue of power framework voltage dependability turns into a power move constraining and capacity factor. A Modern power electronics innovation FATCS based gadget Static Synchronous Series Compensator (SSSC) is a VSC based series FACTS gadget. Bound together power flow controller (UPFC) is to control power flow, voltage magnitude, and phase point. In this examination paper proposed to keep up the voltage magnitude just as power flow of broken lines. The result of change of the power framework parameters, for example, voltage, phase point, dynamic power, responsive power, and in general power factor with and without SSSC and UPFC have additionally been consolidated. Assessment of power framework security is important in the public arena to create approaches to keep up framework activity when at least one segments come up short. A power framework is "secure" when it can resist the loss of at least one fixings and still continue working without serious issues. The Contingency occasion examination strategy is taken to recognize electrical hub power flow in the flawed transmission lines. The Performance of power framework is checked on IEEE 14-Bus System.
\end{abstract} flow.

Keywords: -- SSSC, UPFC, Contingency technique, Power

\section{INTRODUCTION}

The ideal quantity of controlled hub power flow through the transmission lines is translated into the required infused voltage. The strength of direct current (D.C) transport voltage assumes significant job in the electrical power flow into the overhead transmission lines. The power stream control is polished by responsive piece of the voltage pervaded. It is also observed that SSSC goes about as capacitor when structure power course through the overhead transmission lines is expanded and as an inductor when power stream is to be diminished. The structure delineated in Fig 1 contains essential course of action of SSSC. For overseeing power stream in the transmission line and voltage enormity at the vehicles we are utilizing SSSC and UPFC as a FACTS contraption surveyed $\pm 70 \mathrm{MVAR}$ and $\pm 150 \mathrm{MVAR}$ autonomously. Nonetheless, the significant transformer has the point of confinement of 300MVA (around 4 to various events). Different veritable favored position through utilization of VSC based SSSC and VSI based UPFC are

Revised Version Manuscript Received on August 19, 2019.

Chandrashekhar S.Hiwarkar, Research Scholar, Priyadarshini College of Engineering, Nagpur, E-Mail : cshiwarkar@gmail.com

Dr. Prakash G. Burade, Professor \& Head, Department of Electrical Engineering, SITRC, Nashik, E-mail: prakash.burade@gmail adequately high value of capacity capacitance and along these lines not financially savvy [1].

\section{WORKING PRINCIPAL OF FACTS DEVICES}

\section{A. Static Synchronous Series Compensator (SSSC)}

The static synchronous series compensation (SSSC) is a series compensation gadget which is associated controller dependent on VSC which is appeared in figure1. The SSSC can be worked either capacitive or inductive infused voltage compensation. On the off chance that the line current by 90 lead in the AC series infused voltage in SSSC, capacitive series voltage compensation is gotten in the transmission line.

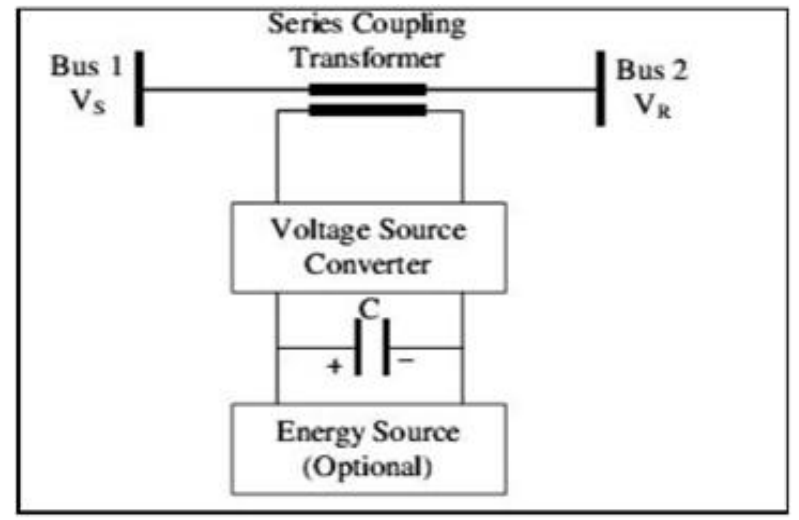

Figure 1: Schematic diagram of SSSC

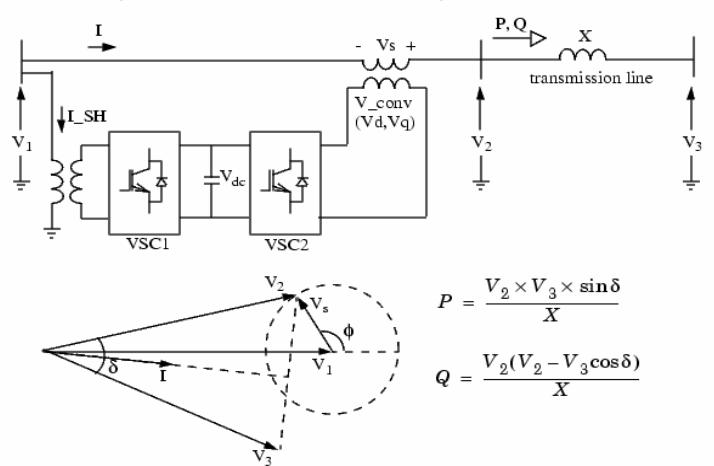

Figure 2: Schematic diagram of UPFC

On the inverse, if the AC line infused series voltage of the SSSC drives the line current by $90^{\circ}$, inductive series compensation can be executed. The infusion of the voltage into the line must occur just when the power is to be subtracted from or included into the line. It is too noticed that SSSC goes about as capacitor when system power course through the line is extended \& inductor when power flow will diminished [1].

Published By:

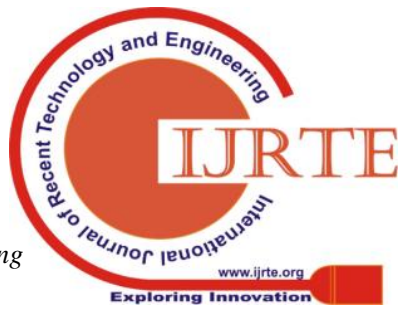




\section{B. Unified Power Flow Controller (UPFC)}

The UPFC comprises of two voltage source converters; series and shunt converter SSSC and STATCOM separately, coupled by means of a typical DC voltage link. The vitality putting away limit of the DC capacitor is commonly low, and after that the shunt converter needs to infuse dynamic power from the transmission matrix in the very same amount as the dynamic power being infused by the series converter.

On the off chance that this isn't pursued, the DC-link voltage may increment or decline concerning the appraised voltage, contingent upon the net power being taken up or returned by the two converters. Under different conditions, the receptive power in the shunt or series converter can be controlled freely, yielding an extraordinary adaptability to the power flow control.

The coupling transformer is used to connect the gadget to the course of action. Figure 2 demonstrates the schematic diagram of three phase UPFC associated with the transmission line. Power flow Control can be accomplished by including the vector of series voltage, Vs with a specific abundancy, $\mid \mathrm{V} \_\mathrm{s}$ |and phase move, $\delta$ to $\mathrm{V} 1$.

This presents another line voltage V2 with another magnitude and phase move. As the edge $\delta$ differs, the phase move $\delta$ somewhere in the range of $\mathrm{V} 1$ and $\mathrm{V} 2$ likewise changes. Figure 2 demonstrates the schematic diagram of the UPFC and qualities of voltage and current [6].

With the nearness of the two converters, UPFC not exclusively can give responsive power yet in addition dynamic power.

In this activity, the series converter swaps both genuine and responsive power with the transmission line. The condition for the dynamic and responsive power is given as pursues:-

$$
\begin{aligned}
& P_{12}=\frac{W_{1} V_{2}}{X_{12}} \sin \delta \\
& Q_{12}=\frac{W_{1} V_{2}}{X_{12}}(\cos \delta+1)
\end{aligned}
$$

\section{GENETIC ALGORITHM}

Genetic calculation is a general enhancement reason calculation, in view of the system of common choice and hereditary genetics.. The procedure begins with accepting an underlying irregular populace created and assessed. Hereditary assessment happens by methods if three essential genetics administrators:

Parent Selection: It is done by picking two chromosomes from the parent people subject to their wellness esteem.

Crossover: It is a critical overseer for the GA. By using this head, two guardians will get joined to outline another chromosome that obtains portions or information set away in parent chromosomes. Starting at as of late, various crossover plans have been proposed, for instance, single point, multipoint, or uniform. In this, a heuristic cross breed has been used.

$$
\mathrm{O}=\mathrm{P} 2+\mathrm{R}(\mathrm{P} 1-\mathrm{P} 2)
$$

$\mathrm{P} 1=$ Parent with the better wellness work

$\mathrm{R}=$ Factor of closeness to the parent c. Mutation: this director is responsible for the mixture of new information. With a little probability, subjective bits of the family chromosomes flip from 0 to 1 and the other way around and give new qualities that don't exist in the parent's populace, in spite of the fact that it is done in genuine method of every factor with utilizing ordinary likelihood conveyance for delivering an irregular whole number in the legitimate furthest reaches of variable.

Following algorithm is developed for selection of faulty lines using FACTS devices.

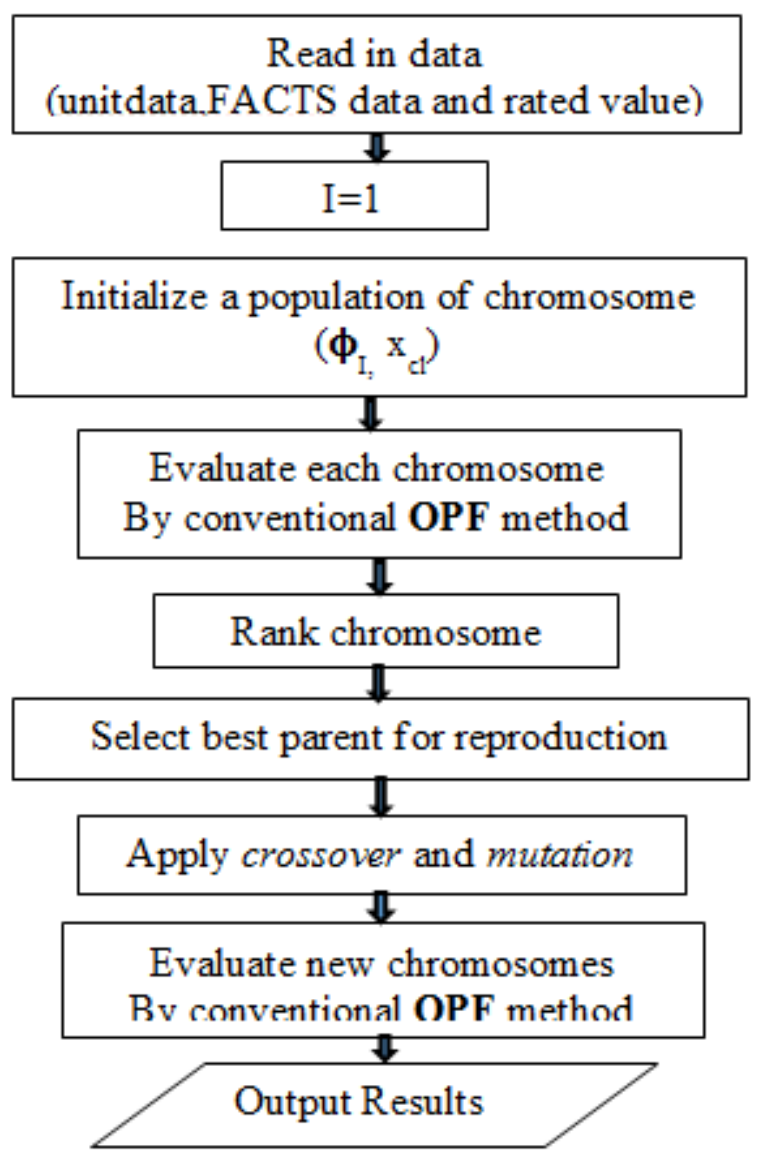

Fig.3 Algorithm for Selection FACTS location. 


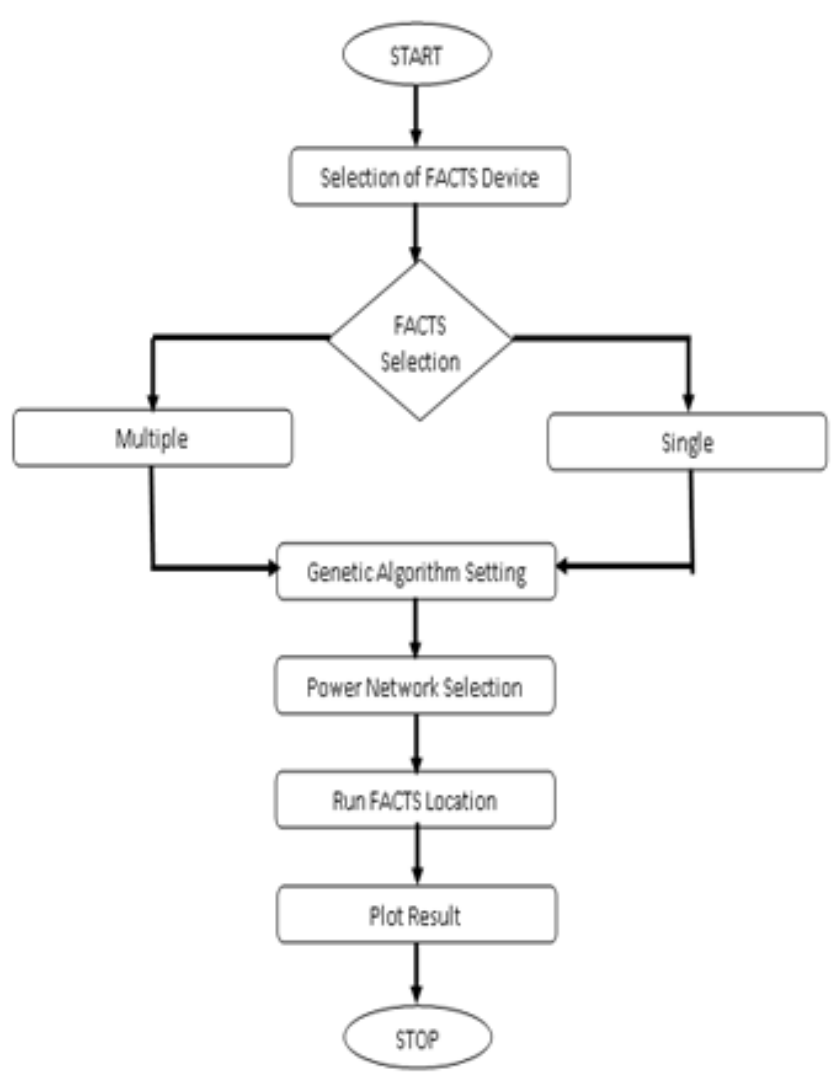

Fig 4. Flow chart of Genetic Algorithm setting

\section{IEEE 14-Bus (Test System)}

The single line graph of the IEEE 14-transport standard test structure is appeared in figure 3, which includes twenty transmission lines. Five no. synchronous machines, including two generators, orchestrated at transports 1 and 2 comparably as three synchronous compensators utilized outstandingly for open power support, masterminded at transports $8,6,3$

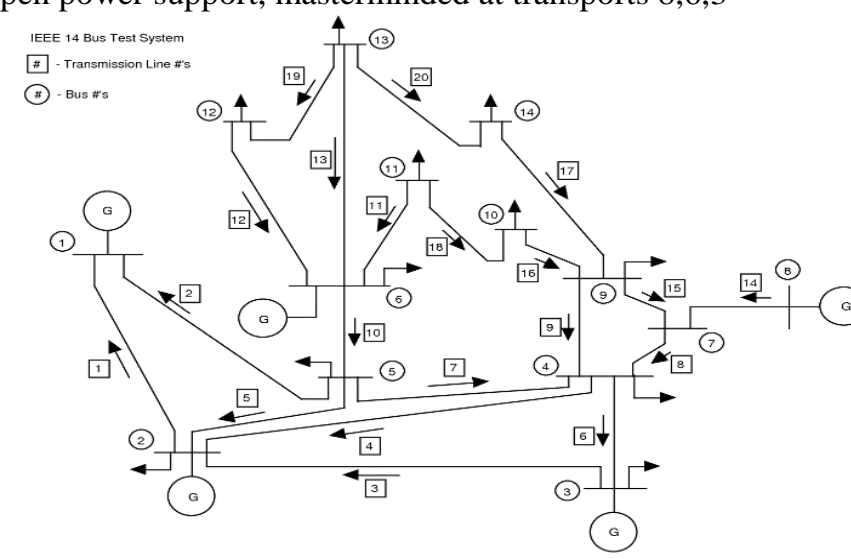

Figure 5: Single line diagram of IEEE 14 Bus

\section{CONTINGENCY SELECTION}

Keeping up power framework security is a standout amongst the most testing functional assignments for the power structure engineers. The security affirmation is an essential errand as it gives the data about the framework when it is in condition of a contingency. Contingency examination method is utilized to choose the impact of issues like disappointments of hardware, transmission line deficiency and so on., and to apply for vital activities to anticipate the power framework precariousness and reliable. The disconnected investigation of individual contingency is a monotonous assignment since power framework contains countless components. As a matter of fact, just chosen possibilities will prompt extreme conditions in power framework. Distinguishing these extreme possibilities is alluded as contingency determination and this can be performed by figuring performance lists for each line [7].

So as to reduce the above issue, a programmed contingency screening approach is being received which distinguishes and positions just those shortcomings which really cause by unusual conditions. Here we are set the contingency screening and positioning for unsymmetrical issue. The fundamental reason for this work is to do the contingency choice by computing the two kinds of performance lists to be specific, dynamic power performance index (PIP) and receptive power performance index (PIQ) for individual line deficiency. (PIQ) have been determined for IEEE-14 transport test framework which is appeared in figure 5 .

Established on the estimations of the PIQ, conceivable outcomes have been positioned where a transmission line possibility inciting the high estimation of PIQ has been positioned 1 and at any rate the values of PIQ have been ranked last. The arrangements of dynamic power flow, receptive power flow in different transmission lines and the transport voltages at the transports have been considered [9]. Since contingency examination strategies include the expectation of the impact of individual contingency cases, the above procedure turns out to be exceptionally monotonous and tedious when the mind boggling power framework system is wide and enormous.

So as to maintain a strategic distance from the above issue of contingency screening or contingency determination procedure observed to be basic issued. Much, it is discovered that all the potential issues don't cause the over-inconvenience voltage or under voltage in the other power structure equipment's. The technique of perceiving the possible results that really go to the infringement of the veritable operational points of confinement is known as probability confirmation.

Examination is Starts from the assurance that is situated one and is continued in till no certified potential results are found. There are two sorts of execution document, which are of exceptional use, these are dynamic power, execution list (PIP) and open power execution record (PIQ). PIP mirrors the infringement of line dynamic power stream and is provided through equation (3).

$$
P I p=\sum_{i=0}^{l}\left(\frac{P_{i}^{i}}{P_{\max }}\right)
$$

Where,

$\mathrm{Pi}=$ Active power flow in line $\mathrm{i}$,

Pimax =Maximum active power flow in line $i$,

$\mathrm{N}$ is the predetermined segment,

$\mathrm{L}$ is the full scale number of transmission lines in the system If $\mathrm{n}$ is a colossal figure, the PI will be a low piece if all power streams are inside cutoff focuses, and it will be greater in case at any rate one transmission lines are over-load, here the estimation of $\mathrm{n}$ has been kept solidarity.

Published By: Blue Eyes Intelligence Engineering 
The most outrageous power stream in each line is resolved using the equation,

Pimax $=\frac{V_{i} V_{j}}{x}$

Where,

$\mathrm{Vi}=$ Voltage at bus $\mathrm{i}$

$\mathrm{Vj}=$ Voltage at bus $\mathrm{j}$

$\mathrm{X}=$ Reactance of the line connecting bus $\mathrm{i}$ and bus $\mathrm{j}$

Another performance index parameter which is used to bus voltage magnitude violations.

It mathematically given by equation 3 ,

$$
P I v=\sum_{i=1}^{N p q}\left\{\frac{2(\text { Vi-Vinom })}{(\text { Vimax-Vimin })}\right\}
$$

Where $\mathrm{Vi}=$ voltage of transport I, Vimax and Vimin are maximum and minimum voltage limits, Vinom is normal of Vimax and Vimin , Npq is absolute types of load transports of framework [12].

\section{CONTINGENCY RANKING OF IEEE-14 BUS SYSTEM}

To realize the Contingency Ranking Following technique is recognized: The AC power weight stream program for probability examination (CA) by getting the Fast Decoupled Load Flow (FDLF) counts that gives a keen reaction for the likelihood examination since it has the upside of system change condition that can be joined and can be related with duplicate issue of potential conceivable outcomes including transmission line blemish without rethinking the structure Jacobian cross section similar sounding word usage. The positioning of line contingency is given in table1.

TABLE 1: Line by Line Contingency Ranking

\begin{tabular}{|c|c|c|c|}
\hline Fault Line No. & PIP & PIQ & Ranking \\
\hline 1 & 1.1693 & 7.3032 & 10 \\
\hline 2 & 0.9807 & 7.6696 & 11 \\
\hline 3 & 1.1654 & 10.0014 & 7 \\
\hline 4 & 0.9999 & 7.3213 & 9 \\
\hline 5 & 0.9820 & 8.8759 & 2 \\
\hline 6 & 0.9640 & 13.2572 & 19 \\
\hline 7 & 0.9915 & 0.3566 & 17 \\
\hline 8 & 1.0747 & 1.1753 & 4 \\
\hline 9 & 0.9807 & 10.5776 & 16 \\
\hline 10 & 1.2396 & 1.6047 & 15 \\
\hline 11 & 1.0142 & 9.5907 & 18 \\
\hline 12 & 1.0127 & 1.8089 & 6 \\
\hline 13 & 1.0569 & 1.3669 & 20 \\
\hline 14 & 1.0072 & 10.4518 & 1 \\
\hline 15 & 1.0759 & 0.0844 & 13 \\
\hline 16 & 1.0114 & 13.3464 & 5 \\
\hline 17 & 1.0164 & 2.3482 & 3 \\
\hline 18 & 1.0030 & 10.5217 & 14 \\
\hline 19 & 1.0008 & 12.5538 & . \\
\hline 20 & 1.0076 & 2.2891 & situting \\
\hline
\end{tabular}

\section{RESULTS AND DISCUSSION}

The structure has an all-out 20 no. Transmission lines, accordingly we study for 20 line probability conditions by mulling over shortcoming on one line at some irregular moment. The introduction records are summed in the above table but comprehend issue in the line no. 16 have remarkable shows huge effect when all is said in done system. The high estimation of PIQ for this deficiency in like manner prescribes that the most essential thought should be given. The possibility has been set by their situating where the most extraordinary possibility is being positioned 1 and the summary has been positioned 20 which is given in table 1 . And after that we investigate one by one transmission line from their contingency positioning and the outcomes are appeared table No. 2, 3, and 4, with SSSC, UPFC and Genetic algorithm (GA).

The varieties in Bus Voltage, dynamic power flow, and responsive power flow with SSSC, UPFC, and Genetic algorithm (GA) are appeared in figure 6, 7, and 8 individually.

TABLE 2: Voltage variations with SSSC, UPFC and GA

\begin{tabular}{|c|c|c|c|c|c|c|}
\hline $\begin{array}{l}\text { Bus } \\
\text { No. }\end{array}$ & $\begin{array}{c}\text { System } \\
\text { Bus } \\
\text { Voltage }\end{array}$ & $\begin{array}{c}\text { Bus Voltage } \\
\text { (After Fault) }\end{array}$ & $\begin{array}{c}\text { Bus Voltage } \\
\text { with SSSC }\end{array}$ & $\begin{array}{c}\text { Bus Voltage } \\
\text { with UPFC }\end{array}$ & $\begin{array}{c}\text { Bus Voltage } \\
\text { with SSSC by } \\
\text { GA }\end{array}$ & $\begin{array}{c}\text { Bus Voltage } \\
\text { with UPFC by } \\
\text { GA }\end{array}$ \\
\hline 1. & 1.06 & 1.06 & 1.06 & 1.06 & 1.06 & 1.06 \\
\hline 2. & 1.045 & 1.045 & 1.045 & 1.045 & 1.045 & 1.045 \\
\hline
\end{tabular}


International Journal of Recent Technology and Engineering (IJRTE) ISSN: 2277-3878, Volume-8 Issue-2S8, August 2019

\begin{tabular}{|c|c|c|c|c|c|c|}
\hline 3. & 1.01 & 0.87011 & 1.02100 & 1.021002 & 1.021002 & 1.02100 \\
\hline 4. & 1.0073 & 0.97664 & 1.02100 & 1.0210003 & 1.0210003 & 1.02100 \\
\hline 5. & 1.0097 & 0.99927 & 1.008 & 1.008 & 1.008 & 1.008 \\
\hline 6. & 1.07 & 1.07 & 1.07 & 1.07 & 1.07 & 1.07 \\
\hline 7. & 1.0512 & 1.04527 & 1.052 & 1.052 & 1.052 & 1.052 \\
\hline 8. & 1.09 & 1.09 & 1.09 & 1.09 & 1.09 & 1.09 \\
\hline $\mathbf{9 .}$ & $\mathbf{1 . 0 4 0 2}$ & $\mathbf{0 . 8 3 1 8 9}$ & $\mathbf{1 . 0 5 0 1}$ & $\mathbf{1 . 0 6 0 1}$ & $\mathbf{1 . 0 5 8}$ & $\mathbf{1 . 0 6 5 0 0 1}$ \\
\hline $\mathbf{1 0 .}$ & $\mathbf{1 . 0 3 5 4}$ & $\mathbf{0 . 8 2 7 5 3}$ & $\mathbf{1 . 0 4 5}$ & $\mathbf{1 . 0 5 5}$ & $\mathbf{1 . 0 4 7}$ & $\mathbf{1 . 0 5 0 1 1 0}$ \\
\hline 11. & 1.047802 & 1.04325 & 1.05120 & 1.051201 & 1.051201 & 1.05120 \\
\hline 12. & 1.049263 & 1.04692 & 1.05210 & 1.0521002 & 1.0521002 & 1.05210 \\
\hline 13. & 1.041987 & 1.03842 & 1.05 & 1.05 & 1.05 & 1.05 \\
\hline 14. & 1.016536 & 1.00780 & 1.026 & 1.026 & 1.026 & 1.026 \\
\hline
\end{tabular}

TABLE 3: Active Power (P) Flow variations with SSSC, UPFC and GA

\begin{tabular}{|c|c|c|c|c|c|}
\hline $\begin{array}{l}\text { Line } \\
\text { No. }\end{array}$ & $\mathrm{P}(\mathrm{MW})$ with Fault & $\mathrm{P}(\mathrm{MW})$ with SSSC & P (MW) with UPFC & $\begin{array}{l}\text { P (MW) with } \\
\text { SSSC by GA }\end{array}$ & $\begin{array}{l}\text { P (MW) with } \\
\text { UPFC by GA }\end{array}$ \\
\hline 1. & 219.075283 & 220.2856 & 220.2856 & 197.2856 & 197.2856 \\
\hline 2. & 103.659327 & 113.9695 & 113.9695 & 113.9695 & 113.9695 \\
\hline 3. & 101.2824595 & 111.3562 & 111.3562 & 111.3562 & 111.3562 \\
\hline 4. & 76.41618162 & 84.01668 & 84.01668 & 84.01668 & 84.01668 \\
\hline 5. & 56.67177715 & 62.30846 & 62.30846 & 62.30846 & 62.30846 \\
\hline 6. & 30.21541055 & 33.22069 & 33.22069 & 33.22069 & 33.22069 \\
\hline 7. & 80.70368075 & 88.73062 & 88.73062 & 88.73062 & 88.73062 \\
\hline 8. & 37.18051888 & 40.87856 & 40.87856 & 40.87856 & 40.87856 \\
\hline 9. & 21.16200502 & 23.26682 & 23.26682 & 23.26682 & 23.26682 \\
\hline 10. & 60.77379923 & 66.81848 & 66.81848 & 66.81848 & 66.81848 \\
\hline 11. & 10.56111051 & 11.61154 & 11.61154 & 11.61154 & 11.61154 \\
\hline 12. & 10.7192474 & 11.7854 & 11.7854 & 11.7854 & 11.7854 \\
\hline 13. & 24.43719185 & 26.86776 & 26.86776 & 26.86776 & 26.86776 \\
\hline 14. & 88.00586319 & 96.75909 & 96.75909 & 96.75909 & 96.75909 \\
\hline 15. & 37.18051888 & 40.87856 & 40.87856 & 40.87856 & 40.87856 \\
\hline 16. & 6.468625687 & 10.112007 & 11.112007 & 11.912007 & 12.81207 \\
\hline 17. & 12.91696097 & 13.983208 & 13.983208 & 14.63208 & 14.63208 \\
\hline 18. & 6.346241153 & 6.907827 & 6.907827 & 7.407827 & 7.407827 \\
\hline 19. & 2.3654228 & 2.600692 & 2.600692 & 2.600692 & 2.600692 \\
\hline 20. & 8.17143581 & 8.984182 & 8.984182 & 8.984182 & 8.984182 \\
\hline
\end{tabular}


TABLE 4: Reactive Power Flow (Q) variations with SSSC, UPFC and GA

\begin{tabular}{|c|c|c|c|c|c|}
\hline $\begin{array}{c}\text { Line } \\
\text { No. }\end{array}$ & Q(MVAR) with Fault & Q(MVAR)with SSSC & $\begin{array}{c}\text { Q(MVAR) with } \\
\text { UPFC }\end{array}$ & $\begin{array}{c}\text { Q(MVAR) with } \\
\text { SSSC by GA }\end{array}$ & $\begin{array}{c}\text { Q(MVAR) with } \\
\text { UPFC by GA }\end{array}$ \\
\hline 1. & 18.84321741 & 18.46079 & 18.46079 & 18.46079 & 18.46079 \\
\hline 2. & 4.466605499 & 4.375956 & 4.375956 & 4.375956 & 4.375956 \\
\hline 3. & 0.607916171 & 0.595578 & 0.595578 & 0.595578 & 0.595578 \\
\hline 4. & 0.81692458 & 0.800345 & 0.800345 & 0.800345 & 0.800345 \\
\hline 5. & 2.421043027 & 2.371908 & 2.371908 & 2.371908 & 2.371908 \\
\hline 6. & 9.147033898 & 8.961395 & 8.961395 & 8.961395 & 8.961395 \\
\hline 7. & 11.87064526 & 11.62973 & 11.62973 & 11.62973 & 11.62973 \\
\hline 8. & 4.393196942 & 4.304037 & 4.304037 & 4.304037 & 4.304037 \\
\hline 9. & 0.857425854 & 0.840024 & 0.840024 & 0.840024 & 0.840024 \\
\hline 10. & 4.148849186 & 4.064648 & 4.064648 & 4.064648 & 4.064648 \\
\hline 11. & 4.366196093 & 4.277584 & 4.277584 & 4.277584 & 4.277584 \\
\hline 12. & 2.120211878 & 2.077182 & 2.077182 & 2.077182 & 2.077182 \\
\hline 13. & 6.373292282 & 6.243946 & 6.243946 & 6.243946 & 6.243946 \\
\hline 14. & 12.94472315 & 12.68201 & 12.68201 & 12.68201 & 12.68201 \\
\hline 15. & 6.817664709 & 6.679304 & 6.679302 & 6.679301 & 6.679300 \\
\hline 16. & 1.62075721 & 1.5878629 & 1.356755 & 1.156755 & 1.026755 \\
\hline 17. & 2.309292709 & 1.974603 & 1.974603 & 1.474603 & 1.474603 \\
\hline 18. & 3.297119189 & 2.740352 & 2.9840352 & 2.710352 & 2.710352 \\
\hline 19. & 0.770169434 & 0.754539 & 0.754539 & 0.754539 & 0.754539 \\
\hline 20. & 2.372649962 & 2.324497 & 2.324497 & 2.324497 & 2.324497 \\
\hline
\end{tabular}

Variation of Voltages

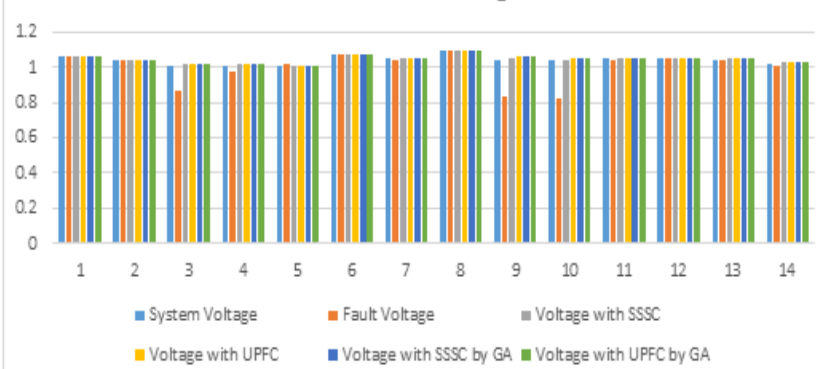

Figure 6 : Voltage variations with Fault, SSSC, UPFC, and GA

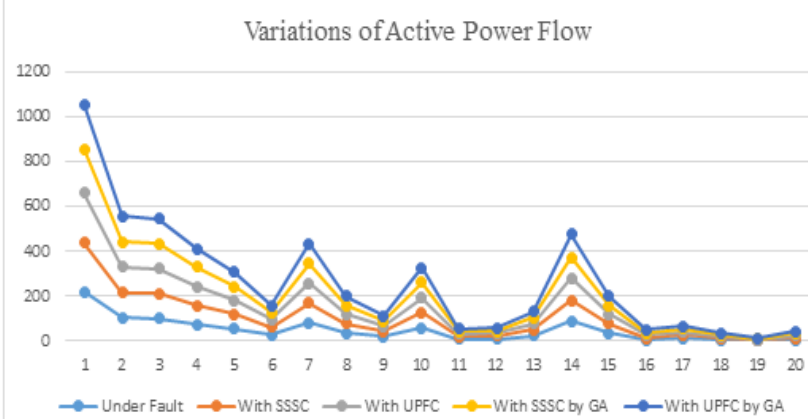

Figure 7 : Active Power flow variations with Fault, SSSC, UPFC, and GA

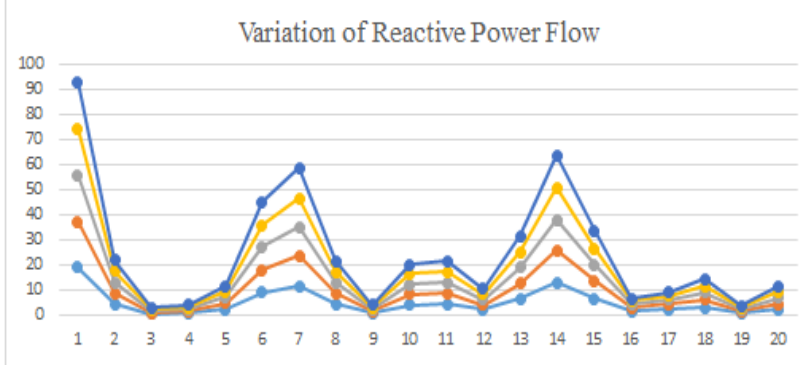

Figure 8 :Reactive Power flow variations with Fault, SSSC, UPFC, and GA

\section{CONCLUSION}

From the outcomes we can see that, the line no. 16 is most serious according to the contingency positioning in this way, the transport voltages under flaw conditions are drops down just as power flow is additionally irritate when contrasted with different lines. In the wake of associating the SSSC and UPFC to defective lines, the outcomes are improved. Be that as it may, results are improved by GA methods connected with FACTS devices.

By basic FACTS device, the transport voltages of broken lines are improved inside a range of 0.06 to 0.4 per unit (pu). Dynamic power flow fluctuates inside a range of $2 \mathrm{MW}$ to 5MW. Reactive Power flow shifts between 0.2 MVAR to 1.5 MVAR.

By Genetic Algorithm, the transport voltages of broken lines are improved inside a range of 0.02 to 0.5 per unit (pu). Dynamic power flow fluctuates inside a range of $2 \mathrm{MW}$ to 7MW. Reactive Power flow fluctuates between 0.2 MVAR to 2.5 MVAR.

\section{REFERENCES}

1. Akhilesh A. Nimje*, Chinmoy Kumar Panigrahi and Ajaya Kumar Mohanty, "Enhanced power transfer capability by using SSSC", Journal of Mechanical Engineering Research Vol. 3 (2), pp. 48-56, February 2011 ISSN 2141 $-2383$.

2. A. Seifi, S.Gholami, and A. Shabanpour, "Power Flow Study and Comparison of FACTS: Series (SSSC), Shunt (STATCOM), and Shunt-Series (UPFC)", the Pacific Journal of Science and Technology Volume 11. Number 1. (May 2010.)

3. Ji-Ho Park and Y.S. Baek, "Coordination Control of Voltage between STATCOM and Reactive Power Compensation Devices in Steady-State" Journal of Electrical Engineering \& Technology Vol. 7, No. 5, pp. 689 697, (2012.) 
4. A. Berizzi, M. Delfanti, P. Marannino, M. Savino, and A. Silvestri, "Enhanced Security-Constrained OPF with FACTS Devices" IEEE Transactions on Power Systems, Vol. 20, No. 3, (August 2005.)

5. J. Zhu, K. Cheung, Senior Member, D. Hwang, and A. Sadjadpour, "Operation Strategy for Improving Voltage Profile and Reducing System Loss" Transactions On Power Systems, Vol. 25, No. 1, (February 2010.)

6. Nashiren.F. Mailah, Senan M. Bashi, "Single Phase Unified Power Flow Controller (UPFC): Simulation and Construction", European Journal of Scientific Research ISSN 1450-216X Vol.30 No.4 (2009), pp.677-684

7. T. Güler, G. Gross, E. Litvinov, and R. Coutu, "On the Economics of Power System Security in Multi-Settlement Electricity Markets", IEEE Transactions on Power Systems, Vol. 26, No. 4, (November 2011.)

8. R. S. Wibowo, N. Yorino, M. Eghbal, Y. Zoka, and Y. Sasaki, "FACTS Devices Allocation With Control Coordination Considering Congestion Relief and Voltage Stability" IEEE Transactions On Power Systems, Vol. 28, No. 2, (May 2013.)

9. T. Mandloi, A. K. Jain "A study of power system security and contingency analysis" International Journal of Scientific Research Engineering \& Technology (IJSRET), ISSN 2278 - 0882 Volume 3, Issue 4, (July 2014.)

10. S. Ravindra, V. C. Veera Reddy, S. Sivanagaraju, "Power System Security Analysis under Generator Outage Condition" International Journal of Advanced Research in Electrical, Electronics and Instrumentation Engineering, Vol. 4, Issue 1, (January 2015.)

11. Dr. P. G. Burade, Dr. J. B. Helonde, "Optimal Location of FACTS devices on Enhancing system security," IJSER, vol.2, issue 4, pp.1-9, (April 2012.)

12. V. P. Doshi, S.A. Salgar, "Latest Trends In Contingency Analysis of Power System" Novateur Publications International Journal of Innovations in Engineering Research and Technology [IJIERT] ISSN: 2394-3696 VOLUME 2, ISSUE 2, (FEB.-2015.)G. O. Young, "Synthetic structure of industrial plastics (Book style with paper title and editor)," in Plastics, 2nd ed. vol. 3, J. Peters, Ed. New York: McGraw-Hill, 1964, pp. 15-64.

\section{AUTHORS PROFILE}

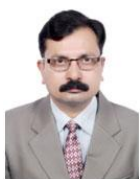

Mr.C. S. Hiwarkar currently working as Assistant Professor in Electrical Engineering Department at KDK College of Engineering, Nagpur, INDIA. He received his B.E. \& M.Tech degree from Electrical Engineering, R.T. M. Nagpur University, INDIA in 1996 \& 2007 respectively. $\mathrm{He}$ is perusing his $\mathrm{Ph} . \mathrm{D}$. in Electrical Engineering from R.T. M. Nagpur University, INDIA. His research interest are in the Power system, FACTS, EHVAC-HVDC transmission system. He has 22 Years teaching experience.

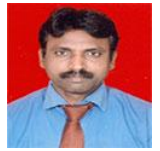

Dr. Prakash G. Burade currently working as a professor,head of Electrical Department and Dean Academics at SITRC,Nashik, India. He obtained Doctorate, PG from Govt. College of engineering, Amravati University and Ph.D. From RTMNU, Nagpur in the year 2007\& 2012 respectively. He has published 35 research papers in reputed international journal and more than 15 papers in international conference. He has vast 23 years' experience in teaching and research. He has travelled to foreign lands as a sitting chair and expert talk at conferences and seminar. He has issued four patents in his recognition. His field of interest is Custom power device, Power Electronics, Power system Optimization and FACTS devices. 